Article

\title{
Postprandial Glycaemic Responses of Dried Fruit-Containing Meals in Healthy Adults: Results from a Randomised Trial
}

\author{
Ruixin Zhu ${ }^{1}$, Zhihong Fan ${ }^{1, *}$, Yang Dong ${ }^{1}$, Manman Liu ${ }^{2}$, Linlin Wang ${ }^{1}$ and Haikun Pan ${ }^{1}$ \\ 1 Beijing Advanced Innovation Centre for Food Nutrition and Human Health, China Agricultural University, \\ Beijing 100083, China; zhuruixin07@126.com (R.Z.); feidi@sina.com (Y.D.); lynn9523@126.com (L.W.); \\ m15201424460_3@163.com (H.P.) \\ 2 Department of Food Science and Engineering, College of Biological Science and Technology, Beijing Forestry \\ University, Beijing 100083, China; manman_Liu@bjfu.edu.cn \\ * Correspondence: daisyfan@cau.edu.cn; Tel.: +86-10-62737717
}

Received: 13 April 2018; Accepted: 28 May 2018; Published: 30 May 2018

\begin{abstract}
The aim of this study was to explore the glycaemic response (GR) patterns of four dried fruits (DF) and the mixed meals containing dried fruits, rice and almonds. Dried apples (DApp), dried jujubes (DJ), raisins (Ra) and dried apricots (DApr) were tested in eleven healthy subjects in random order. Test meals included the following 3 groups: (1) dried fruits containing $50 \mathrm{~g}$ available carbohydrates; (2) mixed meals consisting of DF and rice (DF $+\mathrm{R})$, each contributing $25 \mathrm{~g}$ available carbohydrates; (3) Group (2) supplemented with $30 \mathrm{~g}$ almonds ( $\mathrm{DF}+\mathrm{R}+\mathrm{A}$ ). The postprandial GR and other characteristics in 240 min were investigated. The GI values of 4 DFs were 43 for DApp, 55 for DJ, 56 for both Ra and DApr. The DApp displayed the smallest amplitude of glycaemic excursion within $240 \mathrm{~min}\left(\mathrm{MAGE}_{0-240}\right)$. Compared with rice, the DApp $+\mathrm{R}$ meal elicited a significantly reduced GR and a smaller MAGE $0-240$ (GI 81 vs. 65). With the addition of almonds, the GIs and MAGE $0-240$ decreased significantly in all $\mathrm{DF}+\mathrm{A}+\mathrm{R}$ combinations except DApp $+\mathrm{R}+\mathrm{A}$. The ratio of total fructose/glucose contents of test meals were negatively correlated to GIs. Dried fruits and nuts may have the potential to mitigate the postprandial GR when jointly introduced into glycaemic management diets.
\end{abstract}

Keywords: glycaemic responses; mixed diets; dried fruits; almonds; dried jujubes

\section{Introduction}

Nuts and dried fruit (DF) are traditional dietary components in many countries, and have been included in healthy diet patterns, such as the Dietary Approaches to Stop Hypertension (DASH) diet [1,2] and the Mediterranean diet (MedDiet) [3], as they are a good source of dietary fibre, potassium, magnesium and antioxidants such as polyphenols [4,5]. The consumption of nuts was encouraged by the American Diabetes Association (ADA) in their nutrition recommendations [6] as their benefits in cardiovascular disease prevention [7] and glycaemic control [8] had been well established. However, in contrast to nuts, DF may not be as easily accepted as a group of healthy food by the diabetic and people of impaired glucose tolerance because these dried fruits are considered to be high in sugar.

Recent studies showed that DFs such as raisins were medium-to-low glycaemic index (GI) food [9-11], and could elicit favourable physiologic responses in terms of insulin secretion and appetite modulating hormones [12]. Raisins were also reported for their benefits to cardiovascular disease risk factors including inflammation status, vascular endothelial functions, lipoprotein profiles [11] and blood pressure control, when consumed as a substitution of highly processed snacks [13]. Dried plums and dried apples showed effects on lowering serum hydroperoxides, C-reaction protein 
and low-density lipoprotein cholesterol (LDL-c) levels [14]. Dried jujubes were traditionally regarded as healthy food and a source of phytochemicals in East Asian countries [15,16]. Based on these previous studies, it is reasonable to investigate the possibility of incorporating DF into a nutritious, low-GI and high-fibre diet, which has been suggested to be beneficial to the people at a high risk of diabetes.

Given the fact that DFs are high in sugar, in order to avoid a shift of the energy balance and macronutrient distribution, the consumption of DF should be considered to be a replacement of other foods rich in sugar or starch. In fact, DFs are traditionally consumed as an ingredient of carbohydrate-based food, such as bread, steamed bread, other baked foods and rice foods, in many cultures. However, the glycaemic response of mixed meal consisting of DFs and starch food, on the basis of the same amount of available carbohydrate, is rarely reported.

Previous studies showed that adding nuts such as almonds into white bread meals could suppress the postprandial glycaemic response [17]. However, the effect of the combination of nuts and DF on blood glucose after a carbohydrate-based meal has not yet been investigated.

The aim of this study was to investigate the effect of several DFs on acute postprandial glycaemia in $240 \mathrm{~min}$, either consumed alone or included in mixed meals of the same level of carbohydrate intake. We also examined the synergic contribution of DFs and nuts on the glycaemic excursion pattern when co-ingested with high-GI white rice.

\section{Experimental Methods}

\subsection{Subjects}

Healthy young volunteers aged between 18 and 25 were recruited through advertisements on the university bulletin board and BBS online. The questionnaires given to subjects contained the following criteria: (1) non-smoker; (2) non-drinker; (3) free from food allergies; (4) stable weight in the past three months; (5) regularly eating three meals and not breakfast skipper; (6) not on diet to gain or to lose weight; (7) not on medication in the past six months; (8) no metabolic disease or impaired glucose tolerance; (9) not in pregnancy. The sample size was calculated using the PASS 13 Power Analysis and Sample Size software (NCSS, Kaysville, UT, USA). It found that the test would have 80\% power to examine a difference $(p<0.05)$ with six subjects in iAUC of $145.5 \mathrm{mmol} / \mathrm{L} \cdot 2 \mathrm{~h}$, assuming that the standard deviation (SD) is lower than $104.4 \mathrm{mmol} / \mathrm{L} \cdot 2 \mathrm{~h}$. These calculations were based on a 2-treatment, randomised, crossover study where they observed a $46.2 \%$ reduction $(145.5 \mathrm{mmol} / \mathrm{L} \cdot 2 \mathrm{~h})$ in iAUC for raisins compared with the glucose control [9]. Eleven potential subjects who met these criteria were invited to the laboratory and involved in additional assessments-an oral glucose tolerance test (OGTT) and GR to rice, both were tested twice. The informed consent forms were signed by all eleven eligible individuals. The study was conducted in accordance with the Declaration of Helsinki and carried out at the College of Food Science and Nutritional Engineering, China Agricultural University. The study protocol was approved by the Ethics Committee of China Agricultural University (ethics number 2015027).

\subsection{Study Design}

The study used a randomised crossover design where participants consumed test meals in a randomised order on seventeen separate mornings. Subjects were enrolled to this study using a single allocate ratio. The wash-out period was one week between each test session. Twenty-four hours before each trial day, the subjects were asked to refrain from drinking coffee or alcoholic beverages, excessive eating, staying up late and strenuous exercise. Participants were instructed to consume the test meal in $15 \mathrm{~min}$. Subjects were served $200 \mathrm{~mL}$ of water in room temperature between 90 and $120 \mathrm{~min}$. They were provided with books, magazines and $\mathrm{Wi}-\mathrm{Fi}$, and were suggested to stay seated during the test session but asked neither to consume food that was not related to the study nor to discuss the test meal. The glucose reference and the pure rice meal samples were tested twice respectively in order to assess the reliability of the study procedure. 


\subsection{Pretreatment of Test Dried Fruits}

Raisins (Vitis vinifera Linn.), dried apples (Malus pumila Mill.), dried jujubes (Ziziphus jujuba Mill.), dried apricots (Armeniaca vulgaris Lam.), and almonds (Armeniaca vulgaris Lam.) were selected as raw materials. Dried fruit portions which contained $50.0 \mathrm{~g}$ of available carbohydrates were put in the Tupperware ${ }^{\circledR}$ containers and stored in a refrigerator at $4{ }^{\circ} \mathrm{C}$. Containers were fetched out $12 \mathrm{~h}$ before the experiment to enable an equilibration to the room temperature.

\subsection{Preparation of Test Meals}

The test meals included three groups: (1) four DFs including raisins (Ra), dried apples (DApp), dried jujubes (DJ) and dried apricots (DApr), each containing $50.0 \mathrm{~g}$ of glucose; (2) mixed meals of $\mathrm{DF}$ and rice $(\mathrm{DF}+\mathrm{R})$, each contributing $25.0 \mathrm{~g}$ of available carbohydrates, including mixed meals of dried apples and rice (DApp $+R)$, mixed meals of raisins and rice $(\mathrm{Ra}+\mathrm{R})$, mixed meals of dried jujubes and rice $(D J+R)$, and mixed meals of dried apricots and rice (DApr $+R)$; (3) mixed meals supplemented with $30.0 \mathrm{~g}$ of almonds as well as the above combination of DF and rice, including the mixed meals of raisin, almonds and rice $(\mathrm{Ra}+\mathrm{A}+\mathrm{R})$, mixed meals of almonds, dried apples and rice $(\mathrm{DApp}+\mathrm{A}+\mathrm{R})$, mixed meals of dried jujubes, almonds and rice $(\mathrm{DJ}+\mathrm{A}+\mathrm{R})$, and mixed meals of dried apricots, almonds and rice (DApr $+A+R)$ as well as mixed meals of almonds and rice $(A+R)$. In the morning of test days, each rice portion $(66.1 \mathrm{~g}$ of japonica rice and $99.0 \mathrm{~g}$ of water) was steamed for $40 \mathrm{~min}$ in a plastic crisper, and served to subjects at $40^{\circ} \mathrm{C}$. The glucose $\left(50.0 \mathrm{~g}\right.$ of Glucolin ${ }^{\mathrm{TM}}$ dissolved in $250 \mathrm{~mL}$ of water in room temperature) and rice containing $50 \mathrm{~g}$ of available carbohydrates were prepared as dual reference foods. The composition of the test meals is shown in Table 1.

Table 1. Composition of test meals (per serving).

\begin{tabular}{|c|c|c|c|c|c|c|c|c|}
\hline Sample & $\begin{array}{l}\text { Polished Rice } \\
\text { (g) }\end{array}$ & $\begin{array}{l}\text { Dried Fruits } \\
\text { (g) }\end{array}$ & $\begin{array}{l}\text { Almonds } \\
\text { (g) }\end{array}$ & $\begin{array}{l}\text { Protein } \\
\text { (g) }\end{array}$ & $\begin{array}{l}\text { Fat } \\
\text { (g) }\end{array}$ & $\begin{array}{c}\mathrm{AC} \\
(\mathrm{g})\end{array}$ & $\begin{array}{c}\text { Dietary Fibre } \\
(\mathrm{g})\end{array}$ & $\begin{array}{c}\text { Energy } \\
\text { (kcal) }\end{array}$ \\
\hline Glucose & - & - & - & - & - & 50.0 & 0 & 200 \\
\hline Rice & 66.1 & - & - & 4.8 & 0.3 & 50.0 & 0.3 & 222 \\
\hline $\mathrm{Ra}$ & - & 75.2 & - & 2.8 & 0.9 & 50.0 & 4.7 & 219 \\
\hline DApp & - & 76.8 & - & 1.8 & 0.2 & 50.0 & 5.5 & 209 \\
\hline DJ & - & 84.0 & - & 3.8 & 0.4 & 50.0 & 5.2 & 219 \\
\hline DApr & - & 90.4 & - & 1.9 & 0.4 & 50.0 & 6.9 & 211 \\
\hline $\mathrm{Ra}+\mathrm{R}$ & 33.1 & 37.6 & - & 3.8 & 0.5 & 50.0 & 3.4 & 220 \\
\hline $\mathrm{DApp}+\mathrm{R}$ & 33.1 & 38.4 & - & 3.3 & 0.2 & 50.0 & 2.8 & 215 \\
\hline DJ + R & 33.1 & 42.0 & - & 4.3 & 0.3 & 50.0 & 2.7 & 220 \\
\hline$A p r+R$ & 33.1 & 45.2 & - & 3.3 & 0.3 & 50.0 & 3.3 & 216 \\
\hline $\mathrm{A}+\mathrm{R}$ & 66.1 & - & 30 & 8.1 & 15.3 & 52.0 & 5.5 & 378 \\
\hline $\mathrm{Ra}+\mathrm{A}+\mathrm{R}$ & 33.1 & 37.6 & 30 & 9.5 & 15.6 & 52.0 & 8.9 & 386 \\
\hline $\mathrm{DApp}+\mathrm{A}+\mathrm{R}$ & 33.1 & 38.4 & 30 & 9.0 & 15.3 & 52.0 & 9.0 & 382 \\
\hline $\mathrm{DJ}+\mathrm{A}+\mathrm{R}$ & 33.1 & 42.0 & 30 & 10.0 & 15.4 & 52.0 & 8.2 & 387 \\
\hline $\mathrm{DApr}+\mathrm{A}+\mathrm{R}$ & 33.1 & 45.2 & 30 & 9.0 & 15.4 & 52.0 & 8.8 & 383 \\
\hline
\end{tabular}

Nutritional data were obtained from the nutrition labelling of manufactures. Ra, raisins; DApp, dried apples; DJ, dried jujubes; DApr, dried apricots; $\mathrm{Ra}+\mathrm{R}$, mixed meal of raisins and rice; DApp $+\mathrm{R}$, mixed meal of dried apples and rice; $D J+R$, mixed meal of dried jujubes and rice; $D A p r+R$, mixed meal of dried apricots and rice; $A+R$, mixed meal of almonds and rice; $\mathrm{Ra}+\mathrm{A}+\mathrm{R}$, mixed meal of raisins, almonds and rice; DApp $+\mathrm{A}+\mathrm{R}, \mathrm{mixed}$ meal of dried apples, almonds and rice; $\mathrm{DJ}+\mathrm{A}+\mathrm{R}$, mixed meal of dried jujubes, almonds and rice; $\mathrm{DApr}+\mathrm{A}+\mathrm{R}, \mathrm{mixed}$ meal of dried apricots, almonds and rice. * AC, available carbohydrates.

\subsection{Chemical Analysis of Test Meals}

The composition of the test meals was analysed as follows. Fructose, glucose and sucrose were analysed using a high-performance liquid chromatography method with evaporative light scattering detection (HPLC-ELSD) [18]. Total acid contents were estimated by potentiometric titration [19]. Pectin were hydrolysed using the method of Ahmed and Labavitch [20]. The uronic acid contents were determined using a colorimetric method according to Filisetti-Cozzi and Carpita [21]. Total dietary fibre contents were examined gravimetrically according to AOAC 985.28 [22]. Total phenolic compound contents were determined with Folin-Ciocalteu reagents according to the method of Singleton et al. [23], and gallic acid was used as a standard phenolic compound. The analysis was carried out on a 
Phenomenex Luna 5u NH2 100 A column with isocratic elution of acetonitrile: water (82.5:17.5, v/v). The oxygen radical absorbing capacity (ORAC) were determined according to Ou et al. [24] using Trolox as a standard compound.

\subsection{Blood Glucose Measurement}

The glycaemic test protocol used was an adopted form that recommended by the Food and Agricultural Organization (FAO) and the World Health Organization (WHO). The subjects were asked to arrive at the laboratory at 8:00 a.m., and their fasting plasma glucose concentrations were tested after a 10-min rest. The test meals were provided by a person who was not involved in data analysis to the subjects at 8:15 a.m., and the finger prick blood samples were collected at 15, 30, 45, 60, 90, 120, $150,180,210$ and 240 min just following the start of the test meal. The second drop of blood was used for testing to avoid possible plasma dilution. Plasma blood glucose concentrations were measured on an ONETOUCH ${ }^{\circledR}$ Ultra $^{\circledR}$ (LifeScan Inc., Milpitas, CA, USA) glucometer using the glucose oxidase method. The glucose oxidase method is considered to perform similarly to a standardized method in terms of evaluating the blood glucose concentrations $[25,26]$.

\subsection{Statistical Analysis}

The GR data were converted to the value of glucose changes from the baseline. The incremental areas under the curve of postprandial GRs (iAUC), the incremental peak of blood glucose concentrations, the maximum amplitudes of glucose excursion in $240 \mathrm{~min}\left(\mathrm{MAGE}_{0-240}\right)$, and the negative area under the curve (NAUC) [27] were calculated. The iAUCs in different periods were calculated using the trapezoidal method [28], ignoring the area beneath the baseline level. The GI was determined from the iAUC areas of each test meal and that of the glucose control. The statistical analysis was performed using the SPSS version 21.0 (SPSS Inc., Chicago, IL, USA) and the data were showed as the means (standard deviations, SD) or the means (standard errors, SE) where appropriate. The blood glucose test values between the meals were compared using a one-way analysis of variance ANOVA, and Tukey's multiple was used to adjust for the multiple comparisons test. The criterion for statistical significance was a two-tailed $p<0.05$. The correlation of data was determined using Pearson correlation analysis.

\section{Results}

\subsection{Subject Characteristics}

All of the eleven subjects completed the 17 blood glucose test sessions. Their baseline characteristics are shown in Table 2.

Table 2. Baseline subject characteristics.

\begin{tabular}{ccc}
\hline Characteristic & \multicolumn{2}{c}{ Value } \\
\cline { 2 - 3 } & Mean & SD (SE) \\
\hline Number of participants $(n)$ & 11 & - \\
Number of females $(n)$ & 7 & - \\
Age (year) & 21.4 & 2.4 \\
Body height $(\mathrm{cm})$ & 164.0 & 3.2 \\
Body weight $(\mathrm{kg})$ & 55.2 & 5.2 \\
BMI $\left(\mathrm{kg} / \mathrm{m}^{2}\right)$ & 20.5 & 1.4 \\
Fat mass $(\%)$ & 22.2 & 2.7 \\
BMR (kcal/d) & 1209 & 58 \\
Fasting plasma glucose (mmol/L) & 4.8 & 0.3 \\
\hline
\end{tabular}

Body composition data are presented as means (SD); plasma glucose data are presented as means (SE).

\subsection{Blood Glucose of Four Dried Fruits}

The curves of postprandial glucose response to four DFs are shown in Figure 1. The peak levels of glucose of all test samples attained at $30 \mathrm{~min}$. Compared with other samples, the glucose level of 
DApp showed a significantly lower increment value (0.6 (SE 0.1), $p=0.020)$ at 15 min and (1.8 (SE 0.2), $p=0.027) 30 \mathrm{~min}$. All DFs elicited significantly lower glucose increment values than those of the rice reference from 90 to $120 \mathrm{~min}(p<0.05)$.

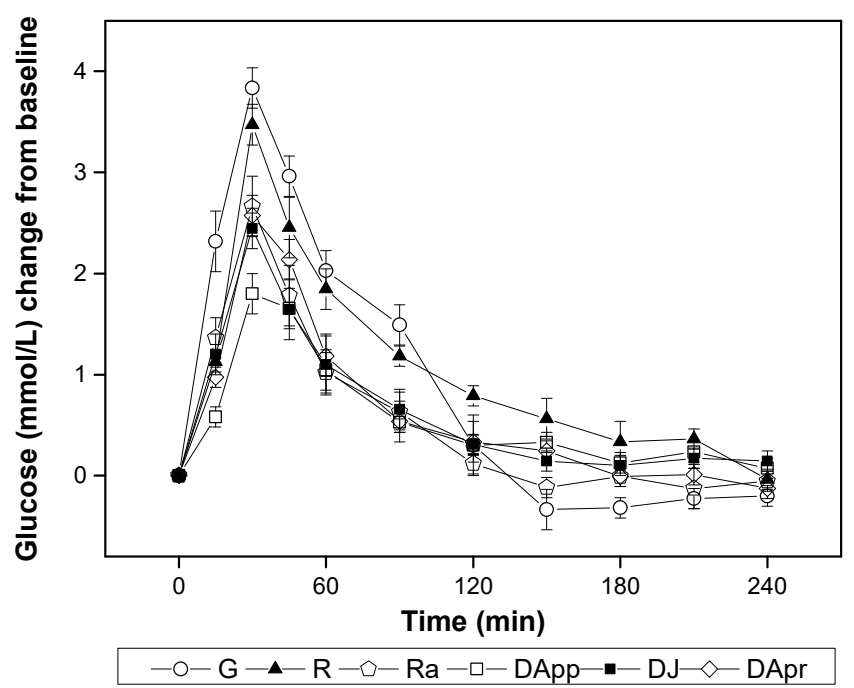

Figure 1. Postprandial plasma glucose changes (mean (SE)) in subjects $(n=11)$ after the consumption of test meals with glucose and rice as references (G, glucose; $R$, rice; Ra, raisins; DApp, dried apples; DJ, dried jujubes; DApr, dried apricots).

\subsection{Blood Glucose of Mixed Meals of Dried Fruits and Rice}

The glycaemic curves of 4 DFs containing meals (half of available carbohydrate from DFs) are shown in Figure 2. The peak level of blood glucose of all mixed meals attained at $30 \mathrm{~min}$. Compared with the blood glucose changes of rice, the $\mathrm{Ra}+\mathrm{R}$ meal elicited a significantly higher increment value (1.7 (SE 0.2), $p=0.021$ ) at $15 \mathrm{~min}$. The DApp + R meal showed a significantly lower increment value (2.0 (SE 0.2), $p=0.033$ ) at $45 \mathrm{~min}$, while $\mathrm{DJ}+\mathrm{R}$ and $\mathrm{Ra}+\mathrm{R}$ had significantly higher increment values $(0.2$ (SE 0.1), $p=0.045 ; 0.2$ (SE 0.1), $p=0.040$, respectively) at $240 \mathrm{~min}$.

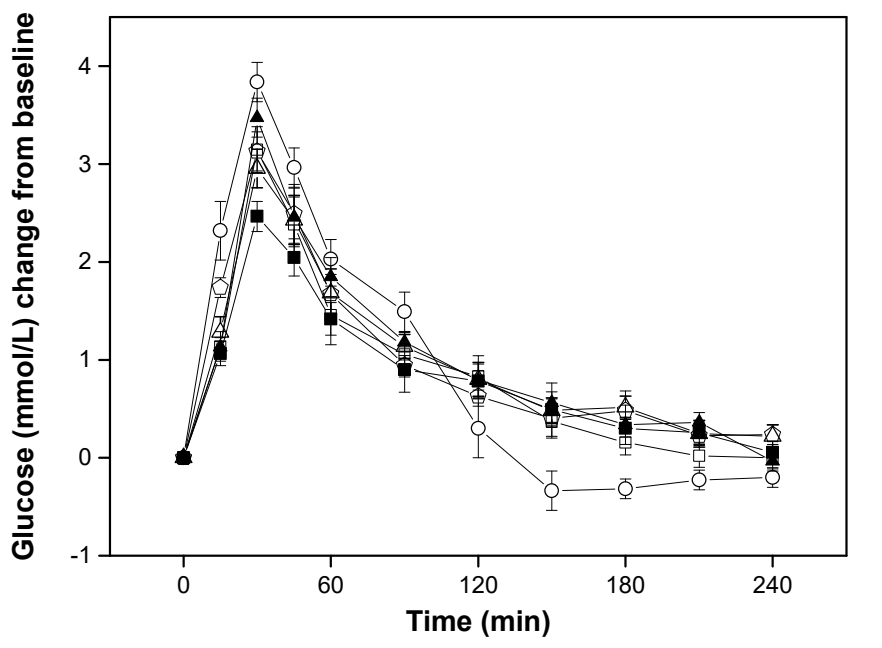

$-O-G-\Delta-R-\square-R a+R-\mathbf{D}-\mathrm{DApp}+\mathrm{R}-\triangle-\mathrm{DJ}+\mathrm{R}-\square-\mathrm{DApr}+\mathrm{R}$

Figure 2. Postprandial plasma glucose changes (mean (SE)) in subjects $(n=11)$ after the consumption of test meals with glucose and rice as references $(G$, glucose; $R$, rice; $R a+R$, mixed meal of raisins and rice; DApp $+\mathrm{R}$, mixed meal of dried apples and rice; $\mathrm{DJ}+\mathrm{R}$, mixed meal of dried jujubes and rice; DApr $+R$, mixed meal of dried apricots and rice). 


\subsection{Blood Glucose of Mixed Meals of Dried Fruits, Almond and Rice}

The combination of almonds and DFs further mitigated the postprandial blood glucose responses of the mixed meals, especially at the $15 \mathrm{~min}$ point, as shown in Figure 3. The peak level of blood glucose of all mixed meals attained at $30 \mathrm{~min}$. Among the four DF-almond mixed meals, only DJ $+\mathrm{A}+\mathrm{R}$ showed a significantly lower increment value (0.7 (SE 0.2), $p=0.041$ ) compared with rice (reference food) at $15 \mathrm{~min}$. There were no differences between the four DF-almond mixed meals in other periods.

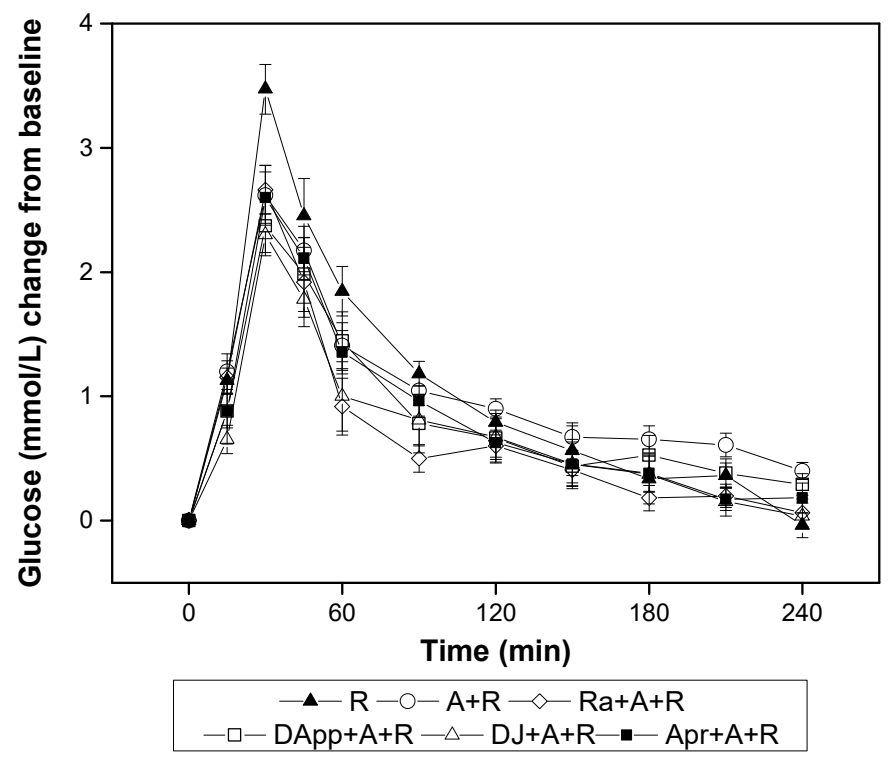

Figure 3. Postprandial plasma glucose changes (mean (SE) in subjects $(n=11)$ after the consumption of test meals with glucose and rice as references $(G$, glucose; $R$, rice; $A+R$, mixed meal of almonds and rice; $\mathrm{Ra}+\mathrm{A}+\mathrm{R}$, mixed meal of raisin, almonds and rice; DApp $+\mathrm{A}+\mathrm{R}$, mixed meal of almonds, dried apples and rice; $\mathrm{DJ}+\mathrm{A}+\mathrm{R}$, mixed meal of dried jujubes, almonds and rice; $\mathrm{DApr}+\mathrm{A}+\mathrm{R}$, mixed meal of dried apricots, almonds and rice.

\subsection{Postprandial Glycaemic Response Characteristics}

As shown in Table 3, the peak values, the $\mathrm{iAUC}_{0-60} \mathrm{~s}, \mathrm{iAUC}_{60-120} \mathrm{~s}$, and $\mathrm{iAUC}_{0-120} \mathrm{~s}$ of DApp, DJ and DApr were significantly smaller than those of the rice reference. The four DFs elicited significantly smaller glycaemic excursions during 240 min compared with the glucose reference, and among which the DApp and DJ had smaller MAGE $0-240$ s compared with that of rice. It is worth noting that from 120 min onwards, the glucose level for the raisin and glucose reference dropped below the baseline, while the blood glucose levels of the DApp, DJ and rice remained constant, above the baseline and produced a significant smaller negative area under curve (NAUC) compared with those of Ra and glucose. The addition of both DApp and DJ caused a significantly reduction in peak values, $\mathrm{iAUC}_{60-120} \mathrm{~S}$ and $\mathrm{MAGE}_{0-240} \mathrm{~s}$ than rice alone, but only DApp $+\mathrm{R}$ produced the smallest $\mathrm{iAUC}_{0-60}$ and $\mathrm{iAUC}_{60-120}$. $\mathrm{Ra}+\mathrm{A}+\mathrm{R}$ and $\mathrm{DJ}+\mathrm{A}+\mathrm{R}$ had a significant reduction of blood glucose values than the $\mathrm{Ra}+\mathrm{R}$ and $\mathrm{DJ}+\mathrm{R}$ did during 0-60 and 60-120 min respectively. Interestingly, the addition of almonds resulted in significant drops in peak values, $\mathrm{iAUC}_{0-120} \mathrm{~s}, \mathrm{MAGE}_{0-240} \mathrm{~s}$ and $\mathrm{GIs}$ in $\mathrm{Ra}+\mathrm{A}+\mathrm{R}$ and $\mathrm{DJ}+\mathrm{A}+\mathrm{R}$, but not in DApp $+\mathrm{A}+\mathrm{R}$, compared with the corresponding mixed meals without almonds.

The GI values of $4 \mathrm{DF}$ s were all significantly lower than that of rice, but there were no differences between 4 DFs, and so did 4 dried fruit-rice mixed meals (Table 4 ). The GI values of DApp $+\mathrm{A}+\mathrm{R}$, $\mathrm{DJ}+\mathrm{A}+\mathrm{R}$ and $\mathrm{Ra}+\mathrm{A}+\mathrm{R}$ were significantly lower than those of $\mathrm{A}+\mathrm{R}$ and $\mathrm{DApr}+\mathrm{A}+\mathrm{R}$, which were already lower than the GI of rice. The GI values of DF with rice were significantly lower than those of DF or DF with rice and almonds, except for DApr $+\mathrm{A}+\mathrm{R}$. 
Table 3. Analysis of postprandial glycaemic response characteristics of test samples within $240 \mathrm{~min}(n=11)$.

\begin{tabular}{|c|c|c|c|c|c|c|c|c|c|c|c|c|c|c|c|}
\hline & \multirow{2}{*}{ Test Meal } & \multicolumn{2}{|c|}{$\mathrm{AUC}_{0-60}$} & \multicolumn{2}{|c|}{$\mathrm{AUC}_{60-120}$} & \multicolumn{2}{|c|}{$\mathrm{AUC}_{0-120}$} & \multicolumn{2}{|c|}{$\mathrm{AUC}_{120-240}$} & \multicolumn{2}{|c|}{ Peak* } & \multicolumn{2}{|c|}{ MAGE $_{0-240}$} & \multicolumn{2}{|c|}{ NAUC } \\
\hline & & Mean & SE & Mean & SE & Mean & SE & Mean & SE & Mean & SE & Mean & SE & Mean & SE \\
\hline \multirow{2}{*}{ Reference } & Glucose & $152.0^{\mathrm{d}}$ & 6.9 & $81.2^{\text {ab }}$ & 9.2 & $233.1^{\mathrm{e}}$ & 13.0 & $10.2^{\mathrm{a}}$ & 1.7 & $3.9^{\mathrm{d}}$ & 0.1 & $4.5^{\mathrm{d}}$ & 0.2 & $-36.7 \mathrm{a}$ & 8.8 \\
\hline & Rice & $119.7^{c}$ & 8.3 & $75.0^{\mathrm{b}}$ & 7.3 & $194.7^{\mathrm{d}}$ & 14.0 & $55.2^{\mathrm{c}}$ & 12.5 & $3.5^{\mathrm{c}}$ & 0.2 & $3.7^{\mathrm{c}}$ & 0.2 & $-6.0^{\mathrm{b}}$ & 3.2 \\
\hline \multirow{6}{*}{ Group (1) } & DApp & $68.4^{\mathrm{a}}$ & 7.6 & $36.1^{\mathrm{a}}$ & 7.1 & $104.5^{\mathrm{a}}$ & 12.4 & $31.2^{b c}$ & 9.4 & $2.1^{\mathrm{a}}$ & 0.2 & $2.2^{\mathrm{a}}$ & 0.2 & $-4.9^{b}$ & 2.7 \\
\hline & DJ & $87.7^{a b}$ & 6.8 & $40.9^{a}$ & 7.1 & $129.3^{\mathrm{ab}}$ & 11.5 & $28.1^{a b c}$ & 8.1 & $2.6^{\mathrm{ab}}$ & 0.2 & $2.8^{\mathrm{b}}$ & 0.2 & $-8.7^{b}$ & 2.7 \\
\hline & $\mathrm{Ra}$ & $94.9 \mathrm{bc}$ & 9.6 & $37.8^{\mathrm{a}}$ & 5.6 & $132.7^{\mathrm{b}}$ & 11.2 & $19.8^{\mathrm{ab}}$ & 8.6 & $2.8^{\mathrm{b}}$ & 0.3 & $3.3^{b c}$ & 0.3 & $-26.5^{a b}$ & 7.3 \\
\hline & DApr & $94.1^{\mathrm{b}}$ & 6.3 & $40.2^{\mathrm{a}}$ & 8.4 & $134.3^{b c}$ & 11.4 & $15.0^{\mathrm{abc}}$ & 7.2 & $2.7^{\mathrm{b}}$ & 0.2 & $3.1^{b c}$ & 0.2 & $-15.0^{\mathrm{ab}}$ & 5.1 \\
\hline & Glucose & $152.0^{\mathrm{c}}$ & 6.9 & $81.2^{\mathrm{a}}$ & 9.2 & $233.1^{c}$ & 13.0 & $10.2^{\mathrm{a}}$ & 1.7 & $3.9^{\mathrm{d}}$ & 0.1 & $4.5^{\mathrm{d}}$ & 0.2 & $-36.7^{a}$ & 8.8 \\
\hline & Rice & $119.7^{b}$ & 8.3 & $75.0^{\mathrm{b}}$ & 7.3 & $194.7^{b}$ & 14.0 & $55.2^{\mathrm{b}}$ & 12.5 & $3.5^{\mathrm{c}}$ & 0.2 & $3.7^{\mathrm{c}}$ & 0.2 & $-6.0^{\mathrm{b}}$ & 3.2 \\
\hline \multirow{6}{*}{ Group (2) } & $\mathrm{DApp}+\mathrm{R}$ & $94.2^{\mathrm{a}}$ & 6.0 & $60.0^{a}$ & 9.7 & $154.2^{\mathrm{a}}$ & 12.2 & $46.2^{\mathrm{b}}$ & 11.2 & $2.5^{a}$ & 0.1 & $2.7^{\mathrm{a}}$ & 0.1 & $-2.3^{b}$ & 1.4 \\
\hline & $\mathrm{DJ}+\mathrm{R}$ & $112.6^{\mathrm{b}}$ & 7.3 & $71.4^{\mathrm{a}}$ & 7.5 & $184.0^{\mathrm{b}}$ & 12.0 & $55.6^{\mathrm{b}}$ & 9.6 & $3.2^{\mathrm{b}}$ & 0.1 & $3.3^{\mathrm{b}}$ & 0.1 & $-3.0^{\mathrm{b}}$ & 1.5 \\
\hline & $\mathrm{Ra}+\mathrm{R}$ & $122.9^{\mathrm{b}}$ & 12.5 & $63.7^{\mathrm{a}}$ & 8.7 & $186.5^{\mathrm{ab}}$ & 15.2 & $53.6^{\mathrm{b}}$ & 27.3 & $3.3^{b c}$ & 0.3 & $3.5^{b c}$ & 0.3 & $-7.4^{\mathrm{b}}$ & 7.7 \\
\hline & $\mathrm{DApr}+\mathrm{R}$ & $110.6^{\mathrm{b}}$ & 6.3 & $66.1^{\mathrm{a}}$ & 8.4 & $176.7^{\mathrm{ab}}$ & 11.4 & $40.1^{\mathrm{b}}$ & 7.2 & $3.3^{b c}$ & 0.2 & $3.6^{\mathrm{bc}}$ & 0.2 & $-11.3^{b}$ & 5.1 \\
\hline & Rice & $119.7^{c}$ & 8.3 & $75.0^{\mathrm{d}}$ & 7.3 & $194.7^{\mathrm{c}}$ & 14.0 & $55.2^{\mathrm{ab}}$ & 12.5 & $3.5^{\mathrm{c}}$ & 0.2 & $3.7^{\mathrm{c}}$ & 0.2 & $-6.0^{\mathrm{b}}$ & 3.2 \\
\hline & $A+R$ & $100.4^{\mathrm{b}}$ & 5.0 & $66.0^{\mathrm{cd}}$ & 5.3 & $166.4^{\mathrm{b}}$ & 8.9 & $79.1^{\mathrm{b}}$ & 9.4 & $2.7^{\mathrm{a}}$ & 0.1 & $2.8^{\mathrm{a}}$ & 0.1 & $-1.5^{a}$ & 1.5 \\
\hline \multirow{4}{*}{ Group (3) } & $\mathrm{DApp}+\mathrm{A}+\mathrm{R}$ & $89.4^{\mathrm{ab}}$ & 8.1 & $55.5^{\mathrm{a}}$ & 6.2 & $144.9 \mathrm{ab}$ & 12.1 & $57.6^{\mathrm{ab}}$ & 8.6 & $2.6^{a}$ & 0.2 & $2.6^{a}$ & 0.2 & $-2.9^{\mathrm{a}}$ & 2.3 \\
\hline & $\mathrm{DJ}+\mathrm{A}+\mathrm{R}$ & $78.5^{\mathrm{a}}$ & 5.8 & $49.4^{a b c}$ & 11.7 & $127.9^{a}$ & 16.0 & $45.0^{\mathrm{a}}$ & 12.9 & $2.5^{\mathrm{a}}$ & 0.2 & $2.7^{\mathrm{a}}$ & 0.2 & $-5.0^{\mathrm{a}}$ & 2.6 \\
\hline & $R a+A+R$ & $92.9^{\mathrm{b}}$ & 7.1 & $37.8^{\mathrm{b}}$ & 5.5 & $130.7^{\mathrm{a}}$ & 10.3 & $38.0^{\mathrm{a}}$ & 6.8 & $2.8^{\mathrm{a}}$ & 0.2 & $2.9^{\mathrm{a}}$ & 0.2 & $-4.3^{\mathrm{a}}$ & 1.8 \\
\hline & $\mathrm{DApr}+\mathrm{A}+\mathrm{R}$ & $94.0^{\mathrm{b}}$ & 5.5 & $58.6^{\text {acd }}$ & 6.2 & $152.7^{\mathrm{ab}}$ & 9.3 & $47.5^{\mathrm{a}}$ & 8.1 & $2.8^{\mathrm{a}}$ & 0.2 & $2.9^{\mathrm{a}}$ & 0.2 & $-5.1^{\mathrm{a}}$ & 3.3 \\
\hline
\end{tabular}

$\mathrm{Ra}$, raisins; DApp, dried apples; DJ, dried jujubes; DApr, dried apricots, Ra $+\mathrm{R}$, mixed meal of raisins and rice; DApp $+\mathrm{R}$, mixed meal of dried apples and rice; DJ + R, mixed meal of dried jujubes and rice; DApr $+R$, mixed meal of dried apricots and rice; $A+R$, mixed meal of almonds and rice; $R a+A+R$, mixed meal of raisin, almonds and rice; DApp $+A+R$, mixed meal of almonds, dried apples and rice; DJ + A + R, mixed meal of dried jujubes, almonds and rice; DApr + A + R, mixed meal of dried apricots, almonds and rice. * The incremental peak of blood glucose value. $a, b, c, d, e$ Mean values within a column with unlike superscript letters are significantly different $(p<0.05)$ 
Table 4. Glycaemic indices (GIs) of test samples $(n=11)$.

\begin{tabular}{cccccccccccccc}
\hline \multirow{2}{*}{ Test Group } & \multicolumn{2}{c}{ Ra } & \multicolumn{2}{c}{ DApp } & \multicolumn{2}{c}{ DJ } & \multicolumn{2}{c}{ DApr } & \multicolumn{2}{c}{ A + R } & \multicolumn{2}{c}{ Rice } \\
\cline { 2 - 12 } & Mean & SE & Mean & SE & Mean & SE & Mean & SE & Mean & SE & Mean & SE & \\
\hline Dried fruits & $56^{\mathrm{abA}}$ & 5 & $43^{\mathrm{abA}}$ & 4 & $55^{\mathrm{abA}}$ & 6 & $56^{\mathrm{abA}}$ & 4 & - & - & $81^{\mathrm{dB}}$ & 4 & $100^{\mathrm{e}}$ \\
Dried fruits + R & $77^{\mathrm{abB}}$ & 8 & $65^{\mathrm{abB}}$ & 5 & $77^{\mathrm{abB}}$ & 6 & $75^{\mathrm{abB}}$ & 7 & - & - & $81^{\mathrm{bB}}$ & 4 & $100^{\mathrm{c}}$ \\
Dried fruits + A + R & $54^{\mathrm{abA}}$ & 2 & $60^{\mathrm{aA}}$ & 4 & $52^{\mathrm{aA}}$ & 4 & $64^{\mathrm{cdB}}$ & 4 & $70^{\mathrm{d}}$ & 4 & $81^{\mathrm{eA}}$ & 4 & $100^{\mathrm{f}}$ \\
\hline
\end{tabular}

$\mathrm{Ra}$, raisins; DApp, dried apples; DJ, dried jujubes; DApr, dried apricots; A + R, mixed meal of almonds and rice. $\mathrm{a}, \mathrm{b}, \mathrm{c}, \mathrm{d}, \mathrm{e}, \mathrm{f}$ Mean values within a row with unlike superscript letters are significantly different $(p<0.05)$. ${ }^{\mathrm{A}, \mathrm{B}}$ Mean values within a column with unlike superscript letters are significantly different $(p<0.05)$.

\subsection{Food Components Relevant to Blood Glucose Management}

Sugar profiles and other components of dried fruits are shown in Tables 5 and 6.

Table 5. Sugar profiles and other components of dried fruits used in test meals.

\begin{tabular}{|c|c|c|c|c|c|c|c|c|}
\hline \multirow{2}{*}{ Nutrient } & \multicolumn{2}{|c|}{ Dried Apples } & \multicolumn{2}{|c|}{ Dried Jujubes } & \multicolumn{2}{|c|}{ Raisins } & \multicolumn{2}{|c|}{ Dried Apricots } \\
\hline & Mean & SD & Mean & SD & Mean & SD & Mean & SD \\
\hline Sucrose $^{\S}(\mathrm{g} / 100 \mathrm{~g})$ & $11.7^{\mathrm{b}}$ & 0.3 & $30.1^{c}$ & 0.6 & $0.1^{\mathrm{a}}$ & 0.0 & $30.1^{\mathrm{c}}$ & 0.6 \\
\hline Glucose ${ }^{\S}(\mathrm{g} / 100 \mathrm{~g})$ & $10.1^{\mathrm{a}}$ & 0.2 & $13.6^{\mathrm{b}}$ & 0.3 & $27.7^{\mathrm{c}}$ & 0.4 & $15.8^{\mathrm{b}}$ & 0.3 \\
\hline Fructose $\S(\mathrm{g} / 100 \mathrm{~g})$ & $39.0^{\mathrm{d}}$ & 0.6 & $19.1^{b}$ & 0.3 & $30.0^{c}$ & 0.6 & $8.1^{\mathrm{a}}$ & 0.1 \\
\hline Total acid (g/100 g) & $1.30^{b}$ & 0.04 & $1.04^{\mathrm{a}}$ & 0.04 & $1.16^{\mathrm{ab}}$ & 0.03 & $1.74^{\mathrm{c}}$ & 0.03 \\
\hline Pectin $(\mathrm{g} / 100 \mathrm{~g})$ & $1.17^{\mathrm{b}}$ & 0.05 & $1.36^{\mathrm{c}}$ & 0.03 & $0.47^{\mathrm{a}}$ & 0.01 & $1.93^{\mathrm{d}}$ & 0.03 \\
\hline Dietary fibre $(\mathrm{g} / 100 \mathrm{~g})$ & $8.7^{\mathrm{c}}$ & 0.3 & $6.2^{\mathrm{a}}$ & 0.2 & $8.8^{\mathrm{c}}$ & 0.2 & $7.0^{\mathrm{b}}$ & 0.2 \\
\hline Total polyphenols (mg GAE/100 g) & $389.8^{b}$ & 9.3 & $457.4^{\mathrm{c}}$ & 10.1 & $683.6^{\mathrm{d}}$ & 13.0 & $151.2^{\mathrm{a}}$ & 7.4 \\
\hline Oxygen radical absorbing capacity (mmol Trolox/100 g) & $26.0^{\mathrm{c}}$ & 1.2 & $9.4^{\mathrm{a}}$ & 0.7 & $30.4^{\mathrm{d}}$ & 1.1 & $13.1^{\mathrm{b}}$ & 0.5 \\
\hline
\end{tabular}

$\S$ Recovery $\geq 95 \%$; ${ }^{a, b, c, d}$ Mean values within a row with unlike superscript letters are significantly different $(p<0.05)$.

Table 6. The percentages of soluble sugar.

\begin{tabular}{ccccc}
\hline Soluble Sugar & Dried Apples & Dried Jujubes & Raisins & Dried Apricots \\
\hline Sucrose * $\%)$ & 19.2 & 47.9 & 0.2 & 55.7 \\
Glucose $*(\%)$ & 16.6 & 21.7 & 47.9 & 29.3 \\
Fructose $^{*}(\%)$ & 64.1 & 30.4 & 51.9 & 15.0 \\
\hline
\end{tabular}

${ }^{*}$ The figures were represented as the percentage in total sugar.

Correlation analysis in Table 7 indicated that the amount of total glucose (the combination of free glucose and the glucose unit in sucrose) in test meals had a significant positive correlation with the $\mathrm{iAUC}_{0-60}, \mathrm{iAUC}_{0-120}$ and NAUC. The ratio of the amount of total fructose and total glucose in test meals had a very strong negative correlation with the iAUC ${ }_{0-60}, \mathrm{iAUC}_{0-120}$ and peak value. No association was found between glycaemic characteristics and the content of the total carbohydrate, dietary fibre, pectin, organic acid or ORAC.

Table 7. Correlation between sugar contents and postprandial GR characteristics of dried fruitcontaining meals.

\begin{tabular}{|c|c|c|c|c|c|c|c|}
\hline Sugar & $\frac{\mathrm{AUC}_{0-60}}{(\mathrm{mmol} / \mathrm{L} \cdot \mathrm{h})}$ & $\frac{\mathrm{AUC}_{60-120}}{(\mathrm{mmol} / \mathrm{L} \cdot \mathrm{h})}$ & $\frac{\mathrm{AUC}_{0-120}}{(\mathrm{mmol} / \mathrm{L} \cdot 2 \mathrm{~h})}$ & $\frac{\mathrm{AUC}_{120-240}}{(\mathrm{mmol} / \mathrm{L} \cdot 2 \mathrm{~h})}$ & $\frac{\text { Peak }}{(\mathrm{mmol} / \mathrm{L})}$ & $\frac{\text { MAGE }_{0-240}}{(\mathrm{mmol} / \mathrm{L})}$ & $\frac{\text { NAUC }}{(\mathrm{mmol} / \mathrm{L} \cdot 4 \mathrm{~h})}$ \\
\hline Fructose & 0.871 & 0.210 & 0.747 & 0.910 & 0.943 & 0.928 & 0.478 \\
\hline Glucose & 0.287 & 0.982 & 0.380 & 0.423 & 0.237 & 0.165 & 0.015 \\
\hline Sucrose & 0.298 & 0.110 & 0.232 & 0.311 & 0.369 & 0.440 & 0.864 \\
\hline Total fructose ${ }^{a}$ & 0.070 & 0.329 & 0.073 & 0.058 & 0.115 & 0.116 & 0.376 \\
\hline Total glucose ${ }^{b}$ & $0.953 *$ & 0.850 & 0.985 * & -0.756 & 0.931 & 0.871 & $0.953 *$ \\
\hline Total fructose/total glucose & $-0.978 *$ & -0.791 & $-0.995^{* *}$ & 0.807 & $-0.957 *$ & -0.915 & 0.624 \\
\hline
\end{tabular}

${ }^{*} p<0.05,{ }^{* *} p<0.01{ }^{\mathrm{a}}$ The combination of free fructose and the fructose unit in sucrose. ${ }^{\mathrm{b}}$ The combination of free glucose and the glucose unit in sucrose. 


\section{Discussion}

The present study demonstrated that the adding of dried fruits to white rice meals, on the basis of isoenergetic exchange for other carbohydrates (the total amount of carbohydrate was kept constant at about $50 \mathrm{~g}$ ), did not increase the GI of the mixed meals, despite of the considerate amount of simple carbohydrates including glucose and fructose. The joint effect of DF and nuts resulted in significant reduction of GI values as well as the glycaemic excursion in $240 \mathrm{~min}$.

To our knowledge, this is the first report on GI value of dried jujubes. Additionally, the GI values of dried apples and dried apricots in the present study were higher than those in previous reports, which were 29 and 30 [29], respectively, while the GI of raisins (56) was comparable to the values for 64 [29], 49 [11] and 49-55 [9] in previous reports. The differences of GI values could be explained by the variety differencesof the DFs, methods used to determine GIs, e.g., the glucose oxidase method, the hexokinase method, the glucose dehydrogenase method, etc., as well as the physiological and ethnic differences of subjects. It was reported that the same sample might elicit a higher postprandial glucose response in Asian subjects compared with that in Western subjects [30].

Given the fact that the GI value of raisins in type 2 diabetes patients was lower than that determined in healthy subjects [31], it could possibly incur hypoglycaemic episodes after $120 \mathrm{~min}$ when ingested in a large amount. The dried apple and dried jujube, which demonstrated stable blood glucose levels through 120-240 min, might be regarded as better snack choice for people of impaired glucose control.

There may be multiple factors affecting the glycaemic properties of DFs, which include: (1) unavailable carbohydrates such as insoluble fibre, oligosaccharides and pectin [32,33]; (2) the amount and profile of sugar, i.e., the contents of glucose, fructose and sucrose [34,35]; (3) digestion enzyme inhibitors such as polyphenols [36]; (4) organic acid [37]; (5) the physical texture and chewy properties of the food [38].

Most of the abovementioned components were determined in this study. It was found that the glycaemic characteristics had no significant correlation with the contents of the total carbohydrate, dietary fibre, pectin, or organic acid. The dried apricot, which had the highest contents of total acid and pectin, and the raisins, which had the highest polyphenol contents and highest ORAC among the four dried fruits, failed to produce low GI values as the dried apple did. An analysis of 121 food GI tests showed that the dietary fibre content had no correlation with GI value [39]. Another study found that neither the carbohydrate content nor the dietary fibre content was the determinant of the GI value of potato varieties [40].

However, the sugar profile seemed to have an important impact on glycaemic responses of dried fruits. High intake of glucose component led to a rapid elevation of blood glucose within $60 \mathrm{~min}$ and a large range of fluctuation. The ratio of the amount of total fructose and total glucose in test meals had a very strong negative correlation with the $\mathrm{iAUC}_{0-60}, \mathrm{iAUC}_{0-120}$ and peak value. The low GI value of apples [29] and its benefit to type 2 diabetes prevention found in prospective cohort studies [41] may partly be explained by the fact that apples had a high content of total fructose and fructose/glucose ratio [4].

Although a large amount of fructose may incur an adverse metabolic impact [34], there is evidence that 'catalytic' doses of fructose from fruits could decrease the glycaemic response to high GI meals in human subjects without any unfavourable effects [42]. Small amounts of fructose have been shown to decrease the hepatic glucose production while accelerate the glycogen production [43], and thus, enhance hepatic glucose metabolism and result in better glycaemic control. A meta-analysis showed that isocaloric exchange of fructose for other carbohydrates could decrease the level of glycated blood proteins without affecting insulin in diabetes patients [34]. However, another meta-analysis of diet-intervention studies found that 26-293 $\mathrm{g}$ of fructose ingestion promoted the development of hepatic insulin resistance in non-diabetic subjects [44]. In the present study, the amount of total fructose in DApp + R, DJ + R and Ra + R diet was calculated to be $16.9 \mathrm{~g}, 12.9 \mathrm{~g}$ and $11.5 \mathrm{~g}$, respectively, 
well below the threshold of $60 \mathrm{~g} /$ day [45]. Such a low dose of isocaloric fructose exposure (35-45 $\mathrm{g}$ dried fruit) is unlikely to incur any adverse effect on other aspects of metabolic control.

A previous study showed that as low as $30 \mathrm{~g}$ of almonds exerted acute post-prandial benefits when added to a high GI carbohydrate-based meal [17]. Preloading protein and fat prior to the ingestion of high carbohydrate could raise glucagon-like peptide 1 (GLP-1) levels and slow gastric empty rates, which contributes to reducing and delaying postprandial glycaemia [46]. However, in the present study, the addition of almond reduced the peak glucose concentrations and the iAUC of the meals without changing the time when peak values were attained.

It is worth noting that in the $\mathrm{Ra}+\mathrm{A}+\mathrm{R}$ meal, the addition of rice to raisins prevented the possible hypoglycaemia after $120 \mathrm{~min}$ which was seen in a pure raisin diet, while the incorporation of almonds effectively attenuated the hyperglycaemia at 15,60 and $90 \mathrm{~min}$ seen in a pure rice or raisin meal. The combinations of almonds, dried fruit and rice could produce a smaller MAGE $\mathrm{E}_{0-240}$ on a fixed amount of carbohydrate-based meal, while the minimised glycaemic excursion in the long term would be desirable for prevention of many complications associated with diabetes [47]. Thus, the mixture of DF and nuts could possibly be developed as a healthy snack, tea break food or preload food for people who need to monitor their blood glucose levels, either the hyperglycaemia or hypoglycaemia patients.

To our knowledge, this is the first report on the joint effect of DF and nuts on glycaemic responses in carbohydrate-based meals. In the present study, all test meals were based on almost equal amounts of carbohydrates, and well accepted by all the subjects. The chemical components including dietary fibre, the pectin content, the polyphenol content, the sugar profile and the organic acid, which were possible contributors to postprandial glucose control, were determined before the blood glucose tests. The correlation analysis between food components and glycaemic characteristics of test meals led to a better explanation of research results.

There are several limitations of the present study. First, the study was carried out on healthy subjects. The results need to be confirmed in people of impaired glucose control in further studies. Second, this is an acute feeding study, which could not be directly extrapolated to a sustainable glycaemic mitigating effect in a longer period of time. Third, the insulinaemic response and the gastrointestinal hormones were not determined in this study, while they would provide a more in-depth glycaemic control mechanism of the mixed diet. Finally, we used a ONETOUCH ${ }^{\circledR}$ Ultra $^{\circledR}$ blood glucose glucometer as a device to measure blood glucose. While a study found this small glucometer met ISO 15197 [48], the evidence of accuracy of it is not strong. So, a comparison ofthe glycaemic responses using a ONETOUCH ${ }^{\circledR}$ Ultra $^{\circledR}$ glucometer and a standard laboratory glucose analyser should be involved in the further study.

In conclusion, the present study demonstrated that dried fruits, including dried apples, dried jujubes, dried apricots and raisins, are medium or low GI foods, which would not elicit the excess rise in blood glucose concentrations when consumed as a substitute of high GI carbohydrate-based food. Moderate amounts of sugar, especially the fructose from dried fruit, may help postprandial glycaemic control. Taking the nutrient profile and antioxidants of dried fruits into account, they may have the potential of being included into a blood-glucose-managing diet without altering the total carbohydrate intake. The combination of dried fruit and nuts could further ensure a small postprandial glycaemic excursion in a diet and the underlying mechanism of their synergic effects deserves future investigation.

Author Contributions: This description will cover the contribution of each author to the research. Z.F., R.Z. and Y.D. formulated the research question. Z.F. and R.Z. designed the study. R.Z., Y.D., M.L., L.W., H.P. carried out the research. R.Z., Y.D. and M.L. analysed the data. Z.F. and R.Z. wrote the article.

Acknowledgments: We sincerely thank all the volunteers participated in the blood glucose tests for their time and corporation.

Conflicts of Interest: The authors declare no conflict of interest. 


\section{References}

1. De Paula, T.P.; Steemburgo, T.; de Almeida, J.C.; Dall'Alba, V.; Gross, J.L.; de Azevedo, M.J. The role of dietary approaches to stop hypertension (DASH) diet food groups in blood pressure in type 2 diabetes. Br. J. Nutr. 2012, 108, 155-162. [CrossRef] [PubMed]

2. Steinberg, D.; Bennett, G.G.; Svetkey, L. The dash diet, 20 years later. JAMA 2017, 317, 1529-1530. [CrossRef] [PubMed]

3. Widmer, R.J.; Flammer, A.J.; Lerman, L.O.; Lerman, A. The Mediterranean diet, its components, and cardiovascular disease. Am. J. Med. 2015, 128, 229-238. [CrossRef] [PubMed]

4. US Department of Agriculture, Agricultural Research Service, Nutrient Data Laboratory. USDA National Nutrient Database for Standard Reference, Release 28 (Revised), Version Current: May 2015. Available online: http:/ / www.ars.usda.gov / ba/bhnrc/ndl (accessed on 30 November 2014).

5. Hernándezalonso, P.; Camachobarcia, L.; Bulló, M.; Salassalvadó, J. Nuts and dried fruits: An update of their beneficial effects on type 2 diabetes. Nutrients 2017, 9, 673. [CrossRef] [PubMed]

6. Association, A.D. Nutrition recommendations and interventions for diabetes a position statement of the American Diabetes Association. Diabetes Care 2007, 30 (Suppl. 1), S61-S78.

7. Luo, C.; Zhang, Y.; Ding, Y.; Shan, Z.; Chen, S.; Yu, M.; Hu, F.B.; Liu, L. Nut consumption and risk of type 2 diabetes, cardiovascular disease, and all-cause mortality: A systematic review and meta-analysis. Am. J. Clin. Nutr. 2014, 100, 256-269. [CrossRef] [PubMed]

8. Jenkins, D.J.; Kendall, C.W.; Banach, M.S.; Srichaikul, K.; Vidgen, E.; Mitchell, S.; Parker, T.; Nishi, S.; Bashyam, B.; De Souza, R.; et al. Nuts as a replacement for carbohydrates in the diabetic diet. Diabetes Care 2011, 34, 1706-1711. [CrossRef] [PubMed]

9. Kim, Y.; Hertzler, S.R.; Byrne, H.K.; Mattern, C.O. Raisins are a low to moderate glycemic index food with a correspondingly low insulin index. Nutr. Res. 2008, 28, 304-308. [CrossRef] [PubMed]

10. Anderson, J.W.; Waters, A.R. Raisin consumption by humans: Effects on glycaemia and insulinaemia and cardiovascular risk factors. J. Food Sci. 2013, 78, A11-A17. [CrossRef] [PubMed]

11. Esfahani, A.; Lam, J.; Kendall, C.W.C. Acute effects of raisin consumption on glucose and insulin responses in healthy individuals. J. Nutr. Sci. 2014, 3, 1-6. [CrossRef] [PubMed]

12. Kaliora, A.C.; Kanellos, P.T.; Gioxari, A.; Karathanos, V.T. Regulation of gip and ghrelin in healthy subjects fed on sun-dried raisins: A pilot study with a crossover trial design. J. Med. Food 2017, 20, 301-308. [CrossRef] [PubMed]

13. Anderson, J.W.; Weiter, K.M.; Christian, A.L.; Ritchey, M.B.; Bays, H.E. Raisins compared with other snack effects on glycemia and blood pressure: A randomized, controlled trial. J. Postgrad. Med. 2014, 126, 37-43. [CrossRef] [PubMed]

14. Chai, S.C.; Hooshmand, S.; Saadat, R.L.; Payton, M.E.; Brummel-Smith, K.; Arjmandi, B.H. Daily apple versus dried plum: Impact on cardiovascular disease risk factors in postmenopausal women. J. Acad. Nutr. Diet. 2012, 112, 1158-1168. [CrossRef] [PubMed]

15. Li, J.W.; Fan, L.P.; Ding, S.D.; Ding, X.L. Nutritional composition of five cultivars of Chinese jujube. Food Chem. 2007, 103, 454-460. [CrossRef]

16. Gao, Q.H.; Wu, C.S.; Wang, M. The jujube (Ziziphus jujuba Mill.) fruit: A review of current knowledge of fruit composition and health benefits. J. Agric. Food Chem. 2013, 61, 3351-3363. [CrossRef] [PubMed]

17. Josse, A.R.; Kendall, C.W.; Augustin, L.S.; Ellis, P.R.; Jenkins, D.J. Almonds and postprandial glycemia-A dose-response study. Metabolism 2007, 56, 400-404. [CrossRef] [PubMed]

18. Ma, C.; Sun, Z.; Chen, C.; Zhang, L.; Zhu, S. Simultaneous separation and determination of fructose, sorbitol, glucose and sucrose in fruits by HPLC-ELSD. Food Chem. 2014, 145, 784-788. [CrossRef] [PubMed]

19. Chen, C.L.; Wang, D.D. Determination of total organic acid content in Schisandra chinensis before and after processing with honey. Strait Pharm. J. 2016, 6, 96-107.

20. Ahmed, A.E.R.; Labavitch, J.M. A simplified method for accurate determination of cell wall uronide content. J. Food Biochem. 2010, 1, 361-365. [CrossRef]

21. Filisetti-Cozzi, T.M.C.C.; Carpita, N.C. Measurement of uronic acids without interference from neutral sugars. Anal. Biochem. 1991, 197, 157-162. [CrossRef]

22. Asp, N.G.; Johansson, C.G.; Hallmer, H.; Siljeström, M. Rapid enzymatic assay of insoluble and soluble dietary fibre. J. Agric. Food Chem. 1983, 31, 476-482. [CrossRef] [PubMed] 
23. Singleton, V.L.; Orthofer, R.; Lamuela-Raventós, R.M. Analysis of total phenols and other oxidation substrates and antioxidants by means of folin-ciocalteu reagent. Method Enzymol. 1999, 299, 152-178.

24. Ou, B.; Huang, D.; Hampsch-Woodill, M.; Flanagan, J.A.; Deemer, E.K. Analysis of antioxidant activities of common vegetables employing oxygen radical absorbance capacity (ORAC) and ferric reducing antioxidant power (FRAP) assays: A comparative study. J. Agric. Food Chem. 2002, 50, 3122-3128. [CrossRef] [PubMed]

25. Lott, J.A.; Turner, K. Evaluation of Trinder's glucose oxidase method for measuring glucose in serum and urine. Clin. Chem. 1975, 21, 1754-1760. [PubMed]

26. Koch, T.R.; Nipper, H.C. Evaluation of automated glucose oxidase methods for serum glucose: Comparison to hexokinase of a colorimetric and an electrometric method. Clin. Chim. Acta 1997, 78, 315-322. [CrossRef]

27. Brand-Miller, J.C.; Stockmann, K.; Atkinson, F.; Petocz, P.; Denyer, G. Glycemic index, postprandial glycemia, and the shape of the curve in healthy subjects: Analysis of a database of more than 1000 foods. Am. J. Clin. Nutr. 2009, 89, 97-105. [CrossRef] [PubMed]

28. Wolever, T.M.S. Effect of blood sampling schedule and method of calculating the area under the curve on validity and precision of glycemic index values. Br. J. Nutr. 2004, 91, 295-300. [CrossRef] [PubMed]

29. Atkinson, F.S.; Foster-Powell, K.; Brand-Miller, J.C. International tables of glycemic index and glycemic load values: 2008. Diabetes Care 2008, 76, 2281-2283. [CrossRef] [PubMed]

30. Henry, C.J.K.; Lightowler, H.J.; Newens, K.; Sudha, V.; Radhika, G.; Sathya, R.M.; Mohan, V. Glycaemic index of common foods tested in the UK and India. Br. J. Nutr. 2008, 99, 840-845. [CrossRef] [PubMed]

31. Kanellos, P.T.; Kaliora, A.C.; Tentolouris, N.K.; Argiana, V.; Perrea, D.; Kalogeropoulos, N.; Kountouri, A.M.; Karathanos, V.T. A pilot, randomized controlled trial to examine the health outcomes of raisin consumption in patients with diabetes. Nutrition 2014, 30, 358-364. [CrossRef] [PubMed]

32. Chandalia, M.; Garg, A.; Lutjohann, D.; von Bergmann, K.; Grundy, S.M.; Brinkley, L.J. Beneficial effects of high dietary fiber intake in patients with type 2 diabetes mellitus. N. Engl. J. Med. 2000, 342, 1392-1398. [CrossRef] [PubMed]

33. Dikeman, C.L.; Fahey, G.C. Viscosity as Related to Dietary Fiber: A Review. Crit. Rev. Food Sci. Nutr. 2006, 46, 649-663. [CrossRef] [PubMed]

34. Cozma, A.I.; Sievenpiper, J.L.; de Souza, R.J.; Chiavaroli, L.; Ha, V.; Wang, D.D.; Mirrahimi, A.; Yu, M.E.; Carleton, A.J.; Di Buono, M.; et al. Effect of fructose on glycemic control in diabetes: A systematic review and meta-analysis of controlled feeding trials. Diabetes Care 2012, 35, 1611-1620. [CrossRef] [PubMed]

35. Evans, R.A.; Frese, M.; Romero, J.; Cunningham, J.H.; Mills, K.E. Fructose replacement of glucose or sucrose in food or beverages lowers postprandial glucose and insulin without raising triglycerides: A systematic review and meta-analysis. Am. J. Clin. Nutr. 2017, 106, 506-518. [CrossRef] [PubMed]

36. Xiao, J.B.; Högger, P. Dietary polyphenols and type 2 diabetes: Current insights and future perspectives. Curr. Med. Chem. 2015, 22, 23-38. [CrossRef] [PubMed]

37. Kang, I.; Buckner, T.; Shay, N.F.; Gu, L.; Chung, S. Improvements in Metabolic Health with Consumption of Ellagic Acid and Subsequent Conversion into Urolithins: Evidence and Mechanisms. Adv. Nutr. 2016, 7, 961-972. [CrossRef] [PubMed]

38. Lee, S.W.; Lee, J.H.; Han, S.H.; Lee, J.W.; Rhee, C. Effect of various processing methods on the physical properties of cooked rice and on in vitro starch hydrolysis and blood glucose response in rats. Starch-Stärke 2005, 57, 531-539. [CrossRef]

39. Bao, J.; Atkinson, F.; Petocz, P.; Willett, W.C.; Brand-Miller, J.C. Prediction of postprandial glycemia and insulinemia in lean, young, healthy adults: Glycemic load compared with carbohydrate content alone. Am. J. Clin. Nutr. 2011, 93, 984-996. [CrossRef] [PubMed]

40. Ek, K.L.; Wang, S.; Brand-Miller, J.; Copeland, L. Properties of starch from potatoes differing in glycemic index. Food Funct. 2014, 5, 2509-2515.

41. Hawkins, M.; Gabriely, I.; Wozniak, R.; Vilcu, C.; Shamoon, H.; Rossetti, L. Fructose improves the ability of hyperglycemia per se to regulate glucose production in type 2 diabetes. Diabetes 2002, 51, 606-614. [CrossRef] [PubMed]

42. Sievenpiper, J.L.; Chiavaroli, L.; De Souza, R.J.; Mirrahimi, A.; Cozma, A.I.; Ha, V.; Wang, D.D.; Matthew, E.Y.; Carleton, A.J.; Beyene, J.; et al. "Catalytic" doses of fructose may benefit glycaemic control without harming cardiometabolic risk factors: A small meta-analysis of randomized controlled feeding trials. Br. J. Nutr. 2012, 108, 418-423. [CrossRef] [PubMed] 
43. Geidl-Flueck, B.; Gerber, P.A. Insights into the hexose liver metabolism-Glucose versus fructose. Nutrients 2017, 9, 1026. [CrossRef] [PubMed]

44. Ter Horst, K.W.; Schene, M.R.; Holman, R.; Romijn, J.A.; Serlie, M.J. Effect of fructose consumption on insulin sensitivity in nondiabetic subjects: A systematic review and meta-analysis of diet-intervention trials. Am. J. Clin. Nutr. 2016, 104, 1562-1576. [CrossRef] [PubMed]

45. Sievenpiper, J.L.; Carleton, A.J.; Chatha, S.; Jiang, H.Y.; De Souza, R.J.; Beyene, J.; Kendall, C.W.; Jenkins, D.J. Heterogeneous effects of fructose on blood lipids in individuals with type 2 diabetes: Systematic review and meta-analysis of experimental trials in humans. Diabetes Care 2009, 32, 1930-1937. [CrossRef] [PubMed]

46. Gentilcore, D.; Chaikomin, R.; Jones, K.L.; Russo, A.; Feinle-Bisset, C.; Wishart, J.M.; Rayner, C.K.; Horowitz, M. Effects of fat on gastric emptying of and the glycemic, insulin, and incretin responses to a carbohydrate meal in type 2 diabetes. J. Clin. Endocrinol. Metab. 2006, 91, 2062-2067. [CrossRef] [PubMed]

47. Rizzo, M.R.; Marfella, R.; Barbieri, M.; Boccardi, V.; Vestini, F.; Lettieri, B.; Canonico, S.; Paolisso, G. Relationships between daily acute glucose fluctuations and cognitive performance among aged type 2 diabetic patients. Diabetes Care 2010, 33, 2169-2174. [CrossRef] [PubMed]

48. DICNS Group. A multicenter study of the accuracy of the one touch ultra home glucose meter in children with type 1 diabetes. Diabetes Technol. Ther. 2003, 5, 933-940.

(c) 2018 by the authors. Licensee MDPI, Basel, Switzerland. This article is an open access article distributed under the terms and conditions of the Creative Commons Attribution (CC BY) license (http://creativecommons.org/licenses/by/4.0/). 